\title{
Notes and Announcements
}

Postgraduate Course: "Peripheral Neuropathies Diagnosis and Management". The Neurology Departments of the Montreal General Hospital and the Massachusetts General Hospital will present this postgraduate course in Montreal, June 2-4, 1983. The course is co-sponsored by the Department of Continuing Medical Education, Harvard Medical School, and the Postgraduate Board of the Montreal General Hospital and McGill University. For further information contact Ms. Carol Zaiman, Postgraduate Board, The Montreal General Hospital, 1650 Cedar Avenue, Montreal, P.Q. H3G 1A4, Canada.

7th European Congress of Neurosurgery. The 7th European Congress of Neurosurgery will be held in Brussels, Belgium from August 28th to September 2nd, 1983. The Scientific Programme includes several breakfast seminars and sponsored conferences in addition to the following main topics:

-advances in the management of intracranial arteriovenous malformations

-the place of surgery in spontaneous brain haematomas

-intracranial nerve repair

-surgery involving the venous systems

-current status of chemotherapy and radiotherapy for cerebral gliomas in adults

-the choice of surgical approach to pituitary adenomas

-hydrocephalus and its management (with the European Association of Neurosurgical Nurses)

-extra-intracranial vascular anastomosis: Longterm results

-research work by young neurosurgeons

The World Federation of Neurosurgical Societies (WFNS) has its traditional committee meetings during the Congress.

A joint meeting organized by the Neurotraumatology Committee of the WFNS in collaboration with the Panafrican Association of Neurological Sciences, on the theme "Medical Traffic Problems in Africa" will be held on Saturday, September 3rd, 1983.

Among the social events, there will be the first International Art Exhibition of painting, ceramics and sculpture by neurosurgeons. Up to now eighteen neurosurgeons from Europe and the United States have entered their names.

\section{For information:}

Secretariat of the 7th European Congress

of Neurosurgery,

Brussels International Conference Center,

Parc des Expositions

B - 1020 Brussels (Belgium)

Telephone $32.2-478.48 .60$ or Telex 23643

International Register of Familial Brain Tumours. An International Register of Familial Brain Tumours (IRFBT) has been established at the Comprehensive Cancer Centre, Leyden, The Netherlands, following the publication of an initial register (Tijssen et al., 1982). The IRFBT is engaged in the active search for new cases of familial brain tumours and would like to invite clinicians worldwide to submit cases, either published or unpublished to this register. Care will be taken to update the register at appropriate times.

Reference: Tijssen CC, Halprin MR, Endtz LJ 1982. Familial Brain Tumours, a commented register. Martinus Nijhoff Publishers, The Hague, Netherlands.

\section{For information:}

IRFBT

Comprehensive Cancer Centre

Vondellaan 47, 2332 AA Leyden, The Netherlands

Third Annual Merritt-Putnam Symposium. The 3rd annual Merritt-Putnam Symposium will be held on Sunday, September 25th, 1983 at Washington Hilton Hotel in Washington, D.C. The subject of this year's symposium will be "Changing Concepts and Newer Diagnostic Methods in Epilepsy". The symposium is sponsored by the American Epilepsy Society, the Epilepsy Foundation of America and the Department of Neurology, College of Physicians \& Surgeons of Columbia University.

\section{For information:}

IntraMed Communications, Inc.,

1633 Broadway,

New York, NY 10019

(212) $265-8027$

\section{Calendar of Events}

June 5-8, 1983. Second International Symposium on BrainHeart Relationship. Jerusalem, Israel. Contact: Prof. S. Stern, P.O.B. 50006, Tel Aviv 61500, Israel.

June 13-17, 1983. European Federation of Child Neurology Societies Meeting. Noordwijkerhout, The Netherlands. Contact: Prof. Dr. Jacobus Willemse, Afdeling Kinderneurologie, Academisch Ziekenhuis, 3500 CG Utrecht, The Netherlands.

June 20-23, 1983. Third Annual International Conference on Computed Tomography of the Head and Spine. La Napoule, France. Contact: Janice Ford, Continuing Education Coordinator, Hospital of the University of Pennsylvania, 3400 Spruce St., Philadelphia, PA 19104.
June 22-25, 1983. XVIII Canadian Congress of Neurological Sciences. St. John's, Nfld. Contact: Wm. Pryse-Phillips, Division of Neurology, Health Sciences Complex, St. John's, Nfld. A 1 B 3 V6.

June 30-July 1, 1983. 2nd Satellite Symposium of the Society of Cerebral Blood Flow and Metabolism. 'Effects of Aging on Regulation of Cerebral Blood Flow and Metabolism'. Deadline for Abstracts is January 31, 1983. Contact: Organizing Secretariat c/o GIBI s.a.s. Mrs. Maria Paola Gerini, 7 via Olona 00198 Roma.

July 1-7, 1983. Seventh International Congress of Endocrinology. Satellite Symposium on the Pineal in association with the Seventh International Congress of En- 
docrinology in Quebec City. Contact: G.M. Brown, Dept. of Neurosciences, McMaster University, 1200 Main St. W., Hamilton, Ontario L8N 3Z5.

July 6-16, 1983. International Society of Chemistry meeting, Vancouver, B.C. Contact: Dr. P.L. McGeer, University of British Columbia, Division of Neurological Sciences, Faculty of Medicine. 2255 Westbrook Mall, Vancouver, B.C. V6T IW5.

July 10-15, 1983. International Society of Neurochemistry. University of British Columbia, Vancouver, B.C. Contact: Dr. P.L. McGeer, University of British Columbia, Div. of Neurological Sciences, Faculty of Medicine, 2255 Westbrook Mall, Vancouver, B.C. V6T 1W5.

August 28-September 2, 1983. International Workshop on Multiple Sclerosis. Erice, Trapani, Sicily. Deadline for applications is June 30,1983. For further information contact: Prof. Clemente Pallotti, M.D., Via Malaguti 1/7 - 40126 Bologna, Italy.

August 31-September 5, 1983. Fourth World Congress on Pain. Seattle, Wash. Contact: L. Jones, Executive Secretary, IASP, 1309 Summit Ave., Room 101, Seattle, WA 98101.

September 10-14, 1983. 8th European Neuroscience Association Meeting. The Hague, The Netherlands.

September 26, 1983. American Epilepsy Society Meeting. Washington, D.C. Contact: Executive Office, 179 Allyn Street, Suite 304, Hartford, Connecticut 06103.
September 26-28, 1983. An Update on Cerebral Vascular Disease. Contact: Dr. V.C. Hachinski, Room 1-3, University Hospital, P.O. Box 5339, Stn. A, London, Ontario, N6A 5 A5.

September 26-30, 1983. 15th Epilepsy International Symposium. Washington, D.C. Contact: Driscoll \& Associates, 1925 North Lynn Street, Suite 1002, Arlington, Virginia, 22209.

October 1-4, 1983. Rossiter Research Conference. "Structure and Function of Biological Membranes". Contact: Rossiter Research Conference, c/o Mrs. Betty Hatch, University Hospital, P.O. Box 5339, Stn. A, London, Ontario, N6A 5 A5.

October 9-13, 1983. VIIth International Congress of Electromyography, Munich. Contact: A. Struppler, Neurologische Klina der Technischen, Universitat, Mohlstrasse 28, 8000 Munchen, 80, FRG.

October 10-15, 1983. VI Pan American Congress of Neurology. Buenos Aires, Argentina. Contact: Dr. Tomas Inausti, Avda Sante Fe 1145 (1059), Buenos Aires, Argentina.

November 6-11, 1983. 13th Annual Meeting, Society for Neuroscience, Boston, MA. Deadline for receipt of abstracts is May 13, 1983. Contact: Nancy Beang, Executive Secretary, Society for Neuroscience, 9650 Rockville Pike, Bethseda, MA 20814.

August 1985. 13th International Congress of Biochemistry. Amsterdam, The Netherlands. 